\title{
Modeling streamflow from coupled airborne laser scanning and acoustic Doppler current profiler data
}

\author{
Norris Lam, Jason W. Kean and Steve W. Lyon
}

\begin{abstract}
The rating curve enables the translation of water depth into stream discharge through a reference cross-section. This study investigates coupling national scale airborne laser scanning (ALS) and acoustic Doppler current profiler (ADCP) bathymetric survey data for generating stream rating curves. A digital terrain model was defined from these data and applied in a physically based 1-D hydraulic model to generate rating curves for a regularly monitored location in northern Sweden. Analysis of the ALS data showed that overestimation of the streambank elevation could be adjusted with a root mean square error (RMSE) block adjustment using a higher accuracy manual topographic survey. The results of our study demonstrate that the rating curve generated from the vertically corrected ALS data combined with ADCP data had lower errors (RMSE $=0.79 \mathrm{~m}^{3} / \mathrm{s}$ ) than the empirical rating curve $\left(\right.$ RMSE $=1.13 \mathrm{~m}^{3} / \mathrm{s}$ ) when compared to streamflow measurements. We consider these findings encouraging as hydrometric agencies can potentially leverage national-scale ALS and ADCP instrumentation to reduce the cost and effort required for maintaining and establishing rating curves

Norris Lam (corresponding author) Steve W. Lyon Department of Physical Geography, Stockholm University,

Stockholm,

10691 ,

Sweden

Bolin Centre for Climate Research, Stockholm University,

Stockholm,

10691

Sweden

E-mail: norris.lam@natgeo.su.se

Jason W. Kean

U.S. Geological Survey,

Denver,

CO 80225

USA at gauging station sites similar to the Röån River.
\end{abstract}

Key words | acoustic Doppler current profiler, airborne laser scanning, rating curve, sweden

\section{INTRODUCTION}

Stream discharge is the basis for practically all hydrological studies. Typically, stream discharge is determined by functionally relating water level (stage) and discharge via a rating curve. The rating curve can be empirically derived from measurements of stage and discharge or theoretically derived from mathematical models. Empirical methods to define rating curves are often time-consuming, dangerous to develop at high flows and can be prone to errors from uncertain measurements of stage and discharge (Pelletier I988; McMillan et al. 20I2). Furthermore, sedimentation processes can lead to rating curve shifts and result in increased uncertainty when not properly considered (Westerberg et al. 20II; Guerrero et al. 20I2). An alternative to empirical methods is to generate rating curves from flow equations or hydraulic models. Producing rating curves through modeling efforts has been shown to be effective for developing stream gauging networks in ungauged basins (Clayton \& doi: $10.2166 /$ nh.2016.257
Kean 20I0), useful for re-establishing rating curves in morphologically unstable rivers (Leonard et al. 2000), and are often accurate relative to traditional gauging methods (Choo et al. 2012; McMillan et al. 2012). However, applying hydraulic models for estimating rating curves can be challenging given the uncertainty typically associated with constraining the impact of channel morphology on flows (Bullard et al. 2007; Legleiter et al. 20II). As such, a central challenge for hydraulic modeling is the collection of accurate river channel and floodplain topography of the stream reach (Casas et al. 2006).

The stream channel geometry required for hydraulic modeling is often acquired through manual cross-sectional surveys of river banks and submerged channels along a stream reach. For example, Reistad et al. (2007) surveyed three Norwegian rivers using a leveling telescope to investigate the applicability of generating rating curves using the 
hydraulic model HEC-RAS. Kean \& Smith (2010) surveyed three gravel-bedded streams with a GPS and two with a total station (TS) and subsequently used a physically based hydraulic model to generate rating curves. Although as demonstrated by these studies accurate elevation data can be obtained through manual methods, the labor costs to survey extensive areas of streams and riparian regions can be significant. Furthermore, traditional survey methods can generally be applied only when the entire stream channel is wadeable; however, when this is not the case (e.g., the water is too deep), other methods need to be sought. In this regard, new technologies offer exciting potential (Harpold et al. 20I5) for evolving our ability to collect stream channel topography for hydraulic modeling.

In recent years, for example, the application of laser scanning technologies to capture stream channel topography has rapidly increased (Hohenthal et al. 20II). Laser scanning is an active remote sensing technology that measures distances to objects by emitting laser light pulses and recording the backscattered energy (Wehr \& Lohr 1999). The distance is resolved by halving the product of the total travel time of each laser pulse and the speed of light in the transmission medium (i.e., air, water). The echo returns can be collected as either discrete returns where only the difference between time of travel and return signal intensity are resolved or as full waveform signals where the entire spectral signature of the backscattered energy is sampled (Glennie et al. 20I3). These laser scanning systems can be mounted on fixed stationary locations such as tripods (Brasington et al. 2012; Hartzell et al. 20I3; Williams et al. 20I5), or borne by aircraft such as helicopters and fixed-wing aircrafts (Wehr \& Lohr I999; Glennie et al. 2013), or mounted on moving vehicles such as boats (Vaaja et al. 2013) and trucks (Barber et al. 2008), or even suspended on wire cables (Lam et al. 20I5).

By and large, topographic mapping with airborne laser scanning (ALS) systems has replaced traditional topographic surveying methods (i.e., photogrammetry) because the laser pulse can penetrate the vegetation canopy to accurately sample the ground elevation. This means that large areas, both vegetated and non-vegetated, can be surveyed in a relatively short amount of time at sub-meter resolution (Shan \& Toth 2009). Via increased areal coverage, there has been growth in the number of national-scale laser scans that have either been completed (Switzerland, Denmark) or are underway (Sweden), and much of these data are freely available (Krishnan et al. 20II; Lantmäteriet 20I2). ALS data have been used to map water surface boundaries (Höfle et al. 2009), delineate flood inundation areas (Casas et al. 2006), and for river flow modeling (Mandlburger et al. 2009). Although much of the literature presents the application of high resolution ALS, Lyon et al. (2015) were able to show that synthetically filtered low resolution ALS data were suitable for generating rating curves in shallow streams. While Lyon et al. (2015) indicated the utility of lower resolution ALS data (i.e., resolutions of about $0.5 \mathrm{pt} / \mathrm{m}^{2}$ ), actual national-scale ALS data were not tested explicitly. Since floodplains and the upper portions of stream banks are relatively stable and change mainly with infrequent floods, using national-scale ALS data to generate rating curves could potentially aid in monitoring and managing water resources across large stream networks.

Although laser scanning has many advantages, some limitations exist when used to capture submerged stream topography or bathymetry. The majority of ALS systems employ an infrared laser pulse (i.e., 1,064 nm) for collecting topographic information. The infrared spectrum is commonly used because the energy is not absorbed by vegetation, thus allowing the emitted laser pulse to travel through the vegetation canopy and reflect off the ground surface. However, infrared energy is strongly absorbed by water which limits the collection of bathymetric information. This problem can be somewhat addressed by employing an additional blue-green laser (i.e., $532 \mathrm{~nm}$ ) to collect stream channel bathymetry (Guenther et al. 1994; Kinzel et al. 2013; McKean et al. 2014) while the infrared laser records terrestrial topography. The primary challenge with bathymetric laser scanners are the corrections required to account for distortions due to the refraction of light at the air-water interface and the change of the laser pulse speed as it travels through the water column (Guenther et al. 200o). Owing to the laser pulses crossing the air-water interface in both the incoming and outgoing directions, distortions due to surface waves can significantly affect the bottom return signal (Guenther et al. 2000; Mandlburger et al. 2015). Sediment load and water quality also affect the strength of the reflected signal and often limit depth measurements to between 1 and 2 Secchi depths (Wang \& Philpot 2007; i.e., 
slightly deeper than the depth a 30-cm Secchi disk is no longer visible). Even though the latest bathymetric ALS systems (e.g., Leica AHAB Hawkeye III, Riegl VQ series, USGS EAARL-B) are designed to better handle turbid waters (e.g., 3.0 Secchi depths), data from these systems are not yet widely available.

Other methods exist to remotely determine bathymetry, including passive optical imagery (Legleiter 2012), hyperspectral imagery (Marcus et al. 2003), and structure from motion with unmanned aerial systems (Woodget et al. 20I5). These image-based techniques show great promise but have been generally limited to streams with shallow depths. This limitation is due to the need for relating image-derived quantities to field depth measurements (i.e., manual surveys). One challenge with spectral-based methods is that a lack of calibration measurements from the deepest and shallowest parts of the river can lead to underestimation and negative depth estimates (Legleiter \& Roberts 2009). A recent hydraulically assisted approach by Legleiter (2015) potentially alleviates the need for field measured depths. The approach was shown to be both robust and accurate; however, application was limited to water depths of less than $2 \mathrm{~m}$ (i.e., wadeable streams). It is therefore important to seek out methods that are appropriate for deeper streams.

A viable option for measuring bathymetry in non-wadeable rivers is to use sonic instruments such as echo-sounders or acoustic Doppler current profilers (ADCP). Although these instruments are similar, echo-sounders are generally dedicated for collecting bathymetry in oceans and lakes while ADCP are usually utilized in rivers to simultaneously collect water depth and water velocity to determine the discharge (Gordon 1996). In general, ADCP are mainly used to resolve only instantaneous discharge; however, when paired with real-time kinematics global positioning systems (RTKGPS), geospatial positioning of the instrument is dramatically improved allowing for georeferencing of bathymetric measurements. In addition to georeferenced depth measurements, the improved spatial positioning of the ADCP boat with RTK-GPS enables accurate positioning of measurements even under mobile bed conditions (Rennie \& Church 20I0; Williams et al. 2015).

When deployed, ADCP instruments are situated just below the water surface which means the emitted sonic pulses do not pass through the air-water interface and corrections for refraction are not required. Water depth and velocity measurements obtained from ADCP have been shown to be accurate and are the preferred method for collecting stream gauging measurements for a number of hydrometric agencies (Mueller \& Wagner 2009; SMHI 20I4). As ADCP are capable of collecting bathymetry and discharge (i.e., typical data required for hydraulic modeling) in non-wadeable waters, these instruments may be among the most viable options for augmenting the current generation of laser scanning data from the perspective of hydrometric agencies. To our knowledge, national-scale ALS (i.e., point densities between 0.5 and $1 \mathrm{pt} / \mathrm{m}^{2}$ ) combined with ADCP bathymetric information to generate streamflow rating curves with a hydraulic model has not yet been tested.

Therefore, the aim of this pilot study is to investigate the ability of coupling national-scale ALS with ADCP bathymetry to generate theoretical rating curves. This study was carried out in northern Sweden using ALS data from the national laser scan database, ADCP bathymetry, and a one-dimensional hydraulic model (Kean \& Smith 2005).

\section{STUDY AREA}

The Röån River was chosen for this pilot study. It is a firstorder stream located at $63.64{ }^{\circ} \mathrm{N}$ and $16.76^{\circ} \mathrm{E}$ in northern Sweden (Figure 1). The $584 \mathrm{~km}^{2}$ catchment consists of rolling hills with a mixture of clay-silt and sandy soils. The river channel is approximately $10 \mathrm{~m}$ wide and moderately sloped along both banks. Riparian vegetation is found along both banks and consists primarily of young willow, alder, tall grasses, and sedges with stem diameters less than $10 \mathrm{~cm}$. The streambed material is composed of gravels and sand. Large roughness elements such as boulders and fallen trees were not observed in the main stream channel. The channel reach is quite straight, considered relatively stable, and excessive bank erosion was not observed along the reach. Like most northern Swedish rivers, the water is brown in color due to the high levels of dissolved organic matter (Ekström 2013). Due to this, the clarity of the water is greatly reduced and the stream bottom is not visible with the naked eye. 

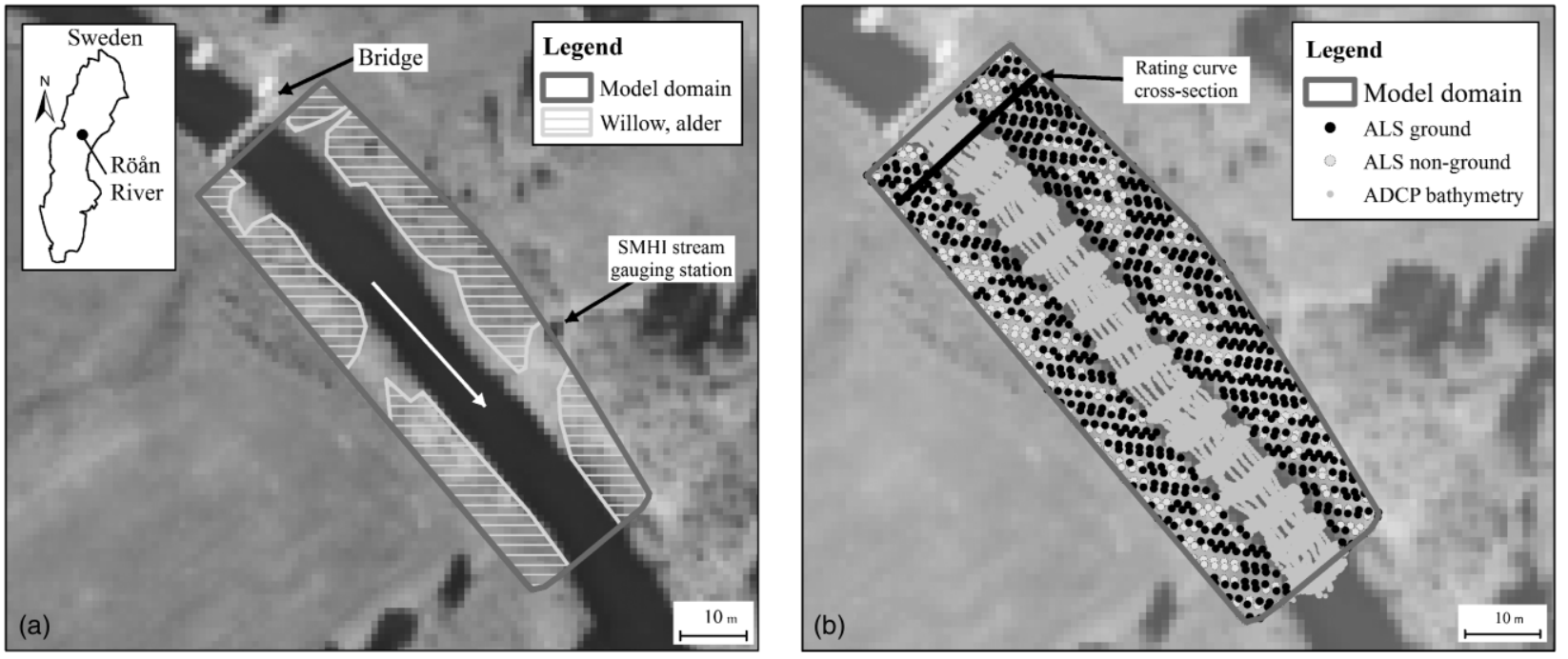

Figure 1 | (a) Overview map and aerial image outlining the Röån River study site. (b) Aerial image showing the ADCP bathymetry and ALS ground and non-ground points classified with LASTOols.

A small pedestrian bridge located at the upstream end of the $10 \mathrm{~m}$ wide and $80 \mathrm{~m}$ long reach of interest (Figure 1) served as the staging platform for the RTK base station and survey equipment deployed in this study (see following sections). The bridge piers were built on the bank edges, and backwater effects were not observed during the field campaign. A stream gauging station operated by the Swedish Meteorological and Hydrological Institute (SMHI) is located at the downstream end of the reach area. The station collects daily averaged stage recorded via a float. According to SMHI's 'Vattenwebb' database (http://vattenwebb.smhi. se/station/), the mean annual discharge in the Röån River is $5.8 \mathrm{~m}^{3} / \mathrm{s}$ with a mean annual minimum and maximum discharge of $1.9 \mathrm{~m}^{3} / \mathrm{s}$ and $15.9 \mathrm{~m}^{3} / \mathrm{s}$, respectively.

A gauging record was provided by SMHI and contained 96 stage-discharge measurements. Metadata regarding the quality of the data were not available but an indicator for the presence of backwater was provided and measurements with backwater effect were excluded from the gauging record. The remaining 38 measurements used to derive the empirical rating curve were collected between 1943 and 2010. The minimum observed discharge from the remaining gauging record was $1.4 \mathrm{~m}^{3} / \mathrm{s}$, the median was $10.5 \mathrm{~m}^{3} / \mathrm{s}$, and the maximum was $21.7 \mathrm{~m}^{3} / \mathrm{s}$. The remaining gauging record did not contain any out of bank flow measurements (i.e., flows greater than about $25 \mathrm{~m}^{3} / \mathrm{s}$ for this site). Discharge measurements from 2008 onwards were collected with a
StreamPro ADCP while measurements previous to 2008 were collected with a current meter (velocity-area method).

\section{$\overline{\text { METHODS }}$}

The aim of this study was to investigate the suitability of generating stream rating curves from stream topography derived from national-scale ALS in combination with ADCP bathymetric survey information. This was accomplished by (1) coupling the ALS and ADCP elevation data into coherent representations of the channel reach and (2) using these data in a one-dimensional hydraulic model to determine rating curves.

\section{Phase 1: Coupling ALS and ADCP data}

\section{ALS data and vertical error correction}

The ALS data used in this study are a subset of the Swedish national laser scanning survey. The data were collected by Lantmäteriet (Swedish Land Survey) in the SWEREF99 TM coordinate system with a target point spacing between 0.5 and $1 \mathrm{pt} / \mathrm{m}^{2}$. The survey at Röån was collected on 28 June 2012, from a fixed-wing mounted Optech ALTM Gemini system (Optech Inc.), which uses a near-infrared laser with a wavelength of $1,064 \mathrm{~nm}$. Due to the strong absorbance of infrared energy by the water, the ALS 
system was not capable of obtaining bathymetric information. A small number of returns were registered along the surface and middle of the stream but these were removed and not considered as bathymetric information. The mean daily stream discharge during the flight mission was reported to be $10.4 \mathrm{~m}^{3} / \mathrm{s}$ by SMHI.

The topographic ALS data were obtained from Lantmäteriet's online repository (http://www.geolex.lm.se/) and delivered as a single scan scene with an average point density of $1 \mathrm{pt} / \mathrm{m}^{2}$. The initial automated processing and classification carried out by Lantmäteriet (Lantmäteriet 20I2) resulted in the three classes: ground, water, and other (Figure 1). According to the technical report, all water areas were classified from pre-existing property and road maps and, therefore, some ground points may have been incorrectly grouped in the water class. Furthermore, visual inspection of the point cloud revealed poorly classified ground point clusters due to the riparian vegetation along the banks. A reclassification of the point cloud was completed using the LASTools software suite (Isenburg 20I5) to minimize the number of misclassified ground and vegetation points due to the original classification. Specifically, the lasground tool was applied to the ALS data and the resulting reclassified ground points were used to generate the nonsubmerged stream channel topography. Within the $25 \mathrm{~m}$ by $80 \mathrm{~m}$ study reach area, the reclassification resulted in 660 ground points compared to 768 points originally classified by Lantmäteriet.

An error evaluation of the reclassified ground elevation was completed according to the American Society of Photogrammetry and Remote Sensing (ASPRS) Positional Accuracy Standards for Digital Geospatial Data (Abdullah et al. 20I5). For elevation errors with a normal distribution, the ASPRS recommends computing the root mean square error (RMSE) statistic to determine the overall vertical accuracy of the data. The RMSE is determined by comparing ALS ground elevation values on a triangulated irregular network (TIN) surface, generated from elevations of an independent source with higher accuracy. The RMSE used in this study was as follows:

$$
R M S E_{Z}=\sqrt{\frac{1}{n} \sum_{j=1}^{n}\left(Z_{j}-\hat{Z}_{j}\right)^{2}}
$$

where $R M S E_{z}$ is the RMSE statistic for elevation, $n$ is the number of elevation points to be compared, $Z_{j}$ is the TIN elevation value for the $j^{\text {th }}$ point, and $\hat{Z}_{j}$ is the elevation from an independent source of higher accuracy.

In this study, the higher accuracy elevations were collected with a Trimble S6 robotic TS and an adjustable prism rod in the SWEREF99 TM coordinate system. The S6 has an angular accuracy of $9.24 \mu \mathrm{rad}$ and a distance accuracy of $\pm 2 \mathrm{~mm}+2 \mathrm{ppm}$ (Trimble 20I3). The survey consisted of 17 cross-sections, spaced approximately $5 \mathrm{~m}$ apart, along the $80 \mathrm{~m}$ stream reach. Topographic information was captured from approximately $0.5 \mathrm{~m}$ instream from the wetted edge and to the top of the channel banks. In total, 605 elevation points were recorded with a linear point spacing of about $0.75 \mathrm{~m}$. The mean vertical error of the reclassified ALS points was removed by vertically adjusting the elevation values with the RMSE statistic. This block adjustment was accomplished using the following equation:

$Z_{\text {corr }}=Z_{\text {orig }}-R M S E_{Z}$

where $Z_{\text {corr }}$ represents the corrected ALS elevation values, $Z_{\text {orig }}$ represents the original ALS elevation value, and $R M S E_{Z}$ represents the RMSE statistic determined from Equation (1).

\section{ADCP data}

The ADCP survey was conducted by a two-person crew on 1 October 2013 and took approximately 3 hours to complete. The survey was collected with a SonTek RiverSurveyor M9 multi-beam ADCP and RTK-GPS receiver in the SWEREF99 TM coordinate system. Both instruments were mounted on a SonTek Hydroboard and the ADCP instrument was set up with a transducer depth of $0.06 \mathrm{~m}$. The M9 is configured with nine transducers where eight are set $25^{\circ}$ from nadir at a spacing of $90^{\circ}$ and the ninth transducer is set vertical and dedicated to bottom tracking (Sontek 20II). Only four of the eight offset transducers are in operation at any given time depending on the depth and flow conditions. The onboard software automatically switches between $3 \mathrm{MHz}$ and $1 \mathrm{MHz}$ for the offset acoustic transducers while the bottom tracking beam operates at a fixed frequency of $0.5 \mathrm{MHz}$. The four offset transducers 
simultaneously collect both bathymetry and water velocity whereas the bottom tracking beam collects only bathymetry.

Positioning of the ADCP was accomplished onboard with the compass, pitch and roll sensors, bottom tracking system, and RTK-GPS. A number of SonTek's M9 instruments have a known deficiency with the internal compass, and affected units need to have the internal compass replaced. The internal compass was replaced for the M9 used in this study. The internal compass was calibrated and validated before the survey without any issues. The additional RTK-GPS information was used to correct the positioning of the ADCP in real time to achieve centimeter-scale positional accuracy. The external RTK base station was set up on the pedestrian bridge (Figure 1) and this provided a clear line of sight between the base station and ADCP during the entire survey (i.e., no communication drop-outs were recorded). In addition to georeferencing the bathymetry, the positioning information was used to calculate moving-bed corrections. These were computed in real time with the RiverSurveyor LIVE! Software (Sontek 20II). A moving-bed test was completed at the beginning of the survey and the influence due to moving-bed was found to be minimal.

The ADCP was deployed using the moving-boat method to collect bathymetric and discharge measurements along 17 evenly spaced cross-sections approximately $5 \mathrm{~m}$ apart. Two passes were made at each cross-section, resulting in 34 individual transects. An average of 236 points was recorded for each transect with a mean length of $9.2 \mathrm{~m}$ and a mean deviation of less than $1 \mathrm{~m}$ from the linear transect across the stream. Three additional passes were made in the up- and downstream directions contributing an additional 4,125 points to the bathymetric survey. In total, 4,361 individual depth measurements were collected in the stream reach and a mean depth of $2.4 \mathrm{~m}$ was observed (Figure 1). The water was too deep to manually collect depth measurements with a total survey and therefore the only bathymetric information used in this study was obtained from the ADCP survey. With regards to the discharge measurements, an average of 22 vertical bins with a mean blanking distance of $0.088 \mathrm{~m}$ was used to determine the discharge and this was found to be $9.23 \mathrm{~m}^{3} / \mathrm{s}$ with a coefficient of variation of 3.9\%.

\section{Digital terrain models of the watercourse}

Coherent digital terrain models (DTMs) of the watercourse were constructed for the study site from (1) vertically corrected ALS (via RMSE correction) and ADCP measurements (hereafter referred to as ALS/ADCP), (2) vertically uncorrected ALS and ADCP measurements (hereafter referred to as UALS/ADCP), and (3) TS and ADCP measurements (hereafter referred to as TS/ADCP). The topographic and bathymetric surveys (i.e., ALS, TS, ADCP) were captured in a common projection system (i.e., SWEREF99 TM) which facilitated a direct spatial merging of the datasets. The georeferencing of the datasets was assumed to be of equal accuracy and effects due to positional uncertainty were not considered in this study. The combined point clouds were interpolated into TIN surfaces and elevation values from the TINs were then mapped onto curvilinear grids with the Multi-Dimensional Surface-Water Modeling System (MD_SWMS) software package (McDonald et al. 2005). Breaklines were used to limit interpolation errors due to the merging of the cross-sectional and areal datasets. The resulting curvilinear grids (i.e., ALS/ADCP, UALS/ ADCP, TS/ADCP) were defined about the channel centerline with a uniform grid spacing of $20 \mathrm{~cm}$ in both crossstream and streamwise directions. The resulting DTMs defined the spatial domains required for the hydraulic model to generate rating curves.

\section{Phase 2: Modeling of rating curves}

Generation of the rating curves in this study was accomplished using the hydraulic model of Kean \& Smith (2005), and the following sections provide a brief overview of the method. Interested readers are referred to Kean \& Smith (2005, 2010) for the full model derivation.

The model can be generalized in two steps. First, flow resistance is quantified from geometric measurements of the (1) channel shape, (2) physical characteristics of the streambed and bank, and (3) size and spacing of the woody vegetation on the banks. Second, the established roughness elements are embedded into a one-dimensional flow model where discharge is calculated along an interpolated grid for a given range of stages to produce a rating curve. 


\section{Bed roughness}

For this study, the channel shape of the streambed and bank were defined from the previously described DTMs. The roughness of the bank and streambed material was described in terms of a roughness height $z_{o}$ which is related to the $84^{\text {th }}$ percentile $\left(D_{84}\right)$ of a pebble size distribution of the stream bed material. The approximation $z_{o}=0.1 D_{84}$ can be used if the bed material can be sampled via a pebble count (Kean \& Smith 2005, 20Io). However, if the bed material cannot be sampled (e.g., water too deep to wade), $z_{o}$ can be empirically determined by inverting the model and back-calculating $z_{o}$ from a single discharge measurement in combination with the water surface slope (Kean \& Smith 2005 - see Section 4.2). Since this was the case in this study, the roughness height for the entire reach was determined empirically from two discharge measurements and their corresponding water-surface slopes. One of the discharge measurements was acquired during the ADCP survey (i.e., low flow) and the other was obtained as a daily mean discharge supplied by SMHI (i.e., mid flow). The low- and mid-flow discharge measurements used in the roughness calibration were $9.23 \mathrm{~m}^{3} / \mathrm{s}$ and $12.04 \mathrm{~m}^{3} / \mathrm{s}$, and their corresponding water surface slopes were $-0.00031 \mathrm{~m} / \mathrm{m}$ and $-0.00038 \mathrm{~m} / \mathrm{m}$, respectively. For both calibration discharges, $z_{o}$ was found to be $0.098 \mathrm{~m}$ for all three DTMs (i.e., ALS/ADCP, UALS/ADCP, TS/ADCP) and was therefore applied for every submerged point on each of the curvilinear grid surfaces. This value was also used over the range of stages for all model domains. While the model is capable of handling spatially heterogeneous roughness values, a homogeneous roughness height was applied across the submerged model grid cells in this study.

\section{Vegetation roughness}

Flow resistance due to vegetation was only considered for woody stems (e.g., willow, alder) and was estimated from two 4- $\mathrm{m}^{2}$ and one $16-\mathrm{m}^{2}$ vegetation density surveys located randomly along both channel banks. Due to the timing of the vegetation survey (i.e., October), there were few leaves left on the woody vegetation. The stem density was determined from the following:

$\alpha=\frac{\sum_{s i}^{D}}{A_{\text {plot }}}=\frac{D_{s}}{\lambda^{2}}$

where $\alpha$ is the vegetation density, $D_{s i}$ is the diameter of a single stem, $A_{\text {plot }}$ is the plot area, $D_{s}$ is the mean stem diameter, and $\lambda$ is the mean spacing. The mean bank vegetation density was $0.23 \mathrm{~m} / \mathrm{m}^{2}$, with a range of $0.19 \mathrm{~m} / \mathrm{m}^{2}$ to $0.26 \mathrm{~m} / \mathrm{m}^{2}$, and was considered representative of the modeled reach. Impacts due to the range of vegetation densities were not considered in this study although previous work has shown the potential impacts to be minimal (Lyon et al. 20I5).

\section{Channel flow model}

The contributing roughness elements described above were incorporated into the second step of the rating model procedure (i.e., hydraulic flow model). The model of Kean \& Smith (2005) determines vertical velocity profiles for every submerged point on a two-dimensional curvilinear grid. This is accomplished by solving the one-dimensional flow equations for steady, non-uniform flow. The equation governing the conservation of mass $(\partial Q / \partial x=0)$ and momentum is:

$\frac{1}{2} \frac{\delta\left(u^{2}\right)_{a v}}{\delta x}+g \frac{\delta E}{\delta x}+\frac{1}{\rho} \frac{\left(\tau_{b}\right)_{a v}}{R}=0$

where $\left(u^{2}\right)_{a v}$ is the square of the downstream velocity component averaged over the cross-section, $x$ is the downstream direction, $g$ is the acceleration of gravity, $E$ is the water surface elevation, $\rho$ is the density of water, $\left(\tau_{b}\right)_{a v}$ is the perimeter-averaged shear stress, and $R$ is the hydraulic radius of the crosssectional area. The first term of Equation (4) describes the streamwise change of velocity, the second term describes pressure-gradient changes due to streamwise changes of water-surface elevation, and the third term describes the resistance contributions.

In streams with steady flow conditions, the cross-sectional average velocity $(u)_{a v}$ and perimeter-averaged shear velocity $\left(u_{*}\right)_{a v}$ are related by a non-dimensional roughness coefficient $\left(\beta_{r}\right)$ for the cross-section which has the form:

$u_{a v}=\beta_{r}\left(u_{*}\right)_{a v}$ 
The perimeter-averaged shear velocity is defined as:

$\left(u_{*}\right)_{a v}=\sqrt{\left(\tau_{b}\right)_{a v} / \rho}=\sqrt{g \frac{A}{P} S_{f}}$

where $S_{f}$ is the friction slope, $A$ is the area of the cross section, and $P$ is the wetted perimeter.

Equation (5) is analogous to the relation between the local, vertically averaged velocity, $\bar{u}$, and the local shear stress, $\tau=\rho g h S_{f}$, such that:

$\bar{u}=\beta\left(h, z_{o}\right) \sqrt{g h S_{f}}=\left(\frac{\ln \left(\frac{h}{z_{0}}\right)-0.74}{\kappa}\right) \sqrt{g h S_{f}}$

where $h$ is the local flow depth, $z_{o}$ is the roughness height, $\beta\left(h, z_{o}\right)$ is the local non-dimensional roughness coefficient, and $\kappa$ is von Karman's constant equal to 0.408 (Long et al. 1993).

The average velocity for the cross-section is found by averaging the local, unit discharge $(\bar{u} h)$, across the cross-section:

$u_{a v}=\frac{1}{A} \int_{-h w r}^{h w l} \beta\left(h, z_{o}\right) \sqrt{g h S_{f}} h d y$

where $y$ is the cross-stream coordinate direction, and $h w l$ and $h w r$ are the left and right half extents of the channel, respectively.

In this study, Equations (4)-(8) were applied to iteratively solve the entire flow field for $0.02-\mathrm{m}$ stage intervals. Discharge at the reference gauge was determined by taking the product of the cross-sectional area and the integrated cross-sectional velocity field for the corresponding stage. This resulted in a single rating curve derived from the coupled ALS and ADCP data.

\section{RESULTS}

\section{ALS elevation correction}

The vertical error correction used in this study was based upon the RMSE calculated from the ALS ground elevation and a TS manual survey. As the usage of the RMSE statistic assumes a normal distribution of the elevation errors, visual and statistical tests for error normality were completed with the MATLAB Statistics Toolbox (The MathWorks Inc.). Figure 2 illustrates the distribution of the elevation residuals as (Figure 2(a)) a normal probability plot and (Figure 2(b)) a histogram of the residuals where both figures indicate that the residuals follow a normal distribution. A one-sampled Kolmogorov-Smirnov test at the 5\% significance level failed to reject the null hypothesis that the residuals follow a normal distribution and, therefore, correcting the mean vertical ALS error with the RMSE statistic was considered suitable. An RMSE of $0.36 \mathrm{~m}$ determined from Equations (1) and (2) was applied as a block correction to the reclassified point cloud (i.e., subtracting the RMSE from all ALS points). This correction reduced the elevation RMSE to $0.17 \mathrm{~m}$, and this corrected point cloud was coupled with the ADCP bathymetric survey.

\section{Accuracy of ALS DTM vs. TS DTM}

We investigated the ability of the coupled ALS and ADCP data for capturing stream channel geometry. This was accomplished by examining the differences for mean stream channel properties between the ALS/ADCP DTM and the reference TS/ADCP DTM as well as for the uncorrected UALS/ADCP DTM and reference TS/ADCP DTM at three representative stages (Table 1). The first comparative stage represents the discharge during the ALS scan which was $10.4 \mathrm{~m}^{3} / \mathrm{s}$ and a stage of $7.6 \mathrm{~m}$. The second stage represents the median observed discharge in the gauging record which was $13.5 \mathrm{~m}^{3} / \mathrm{s}$ at a stage of $7.8 \mathrm{~m}$. The third stage represents the maximum observed discharge in the gauging record which was $20.0 \mathrm{~m}^{3} / \mathrm{s}$ at a stage of $8.1 \mathrm{~m}$. As the ALS and the high-resolution ground surveys were combined with the same bathymetric information, any differences in the comparison are attributed to the differences between the non-submerged portions of the DTMs (i.e., ALS and TS).

In general, both the ALS- and UALS-derived DTMs slightly underestimated the majority of channel properties where the greatest variability was seen for the mean top width and the mean wetted perimeter (Table 1). The largest difference in mean top width of the ALS DTM was found to 
(a)

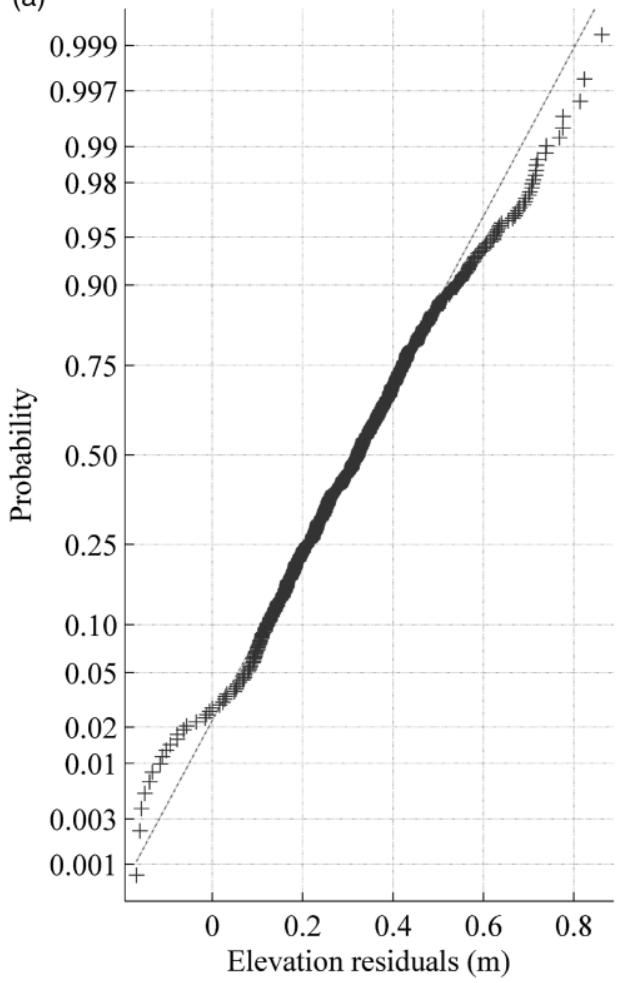

(b)

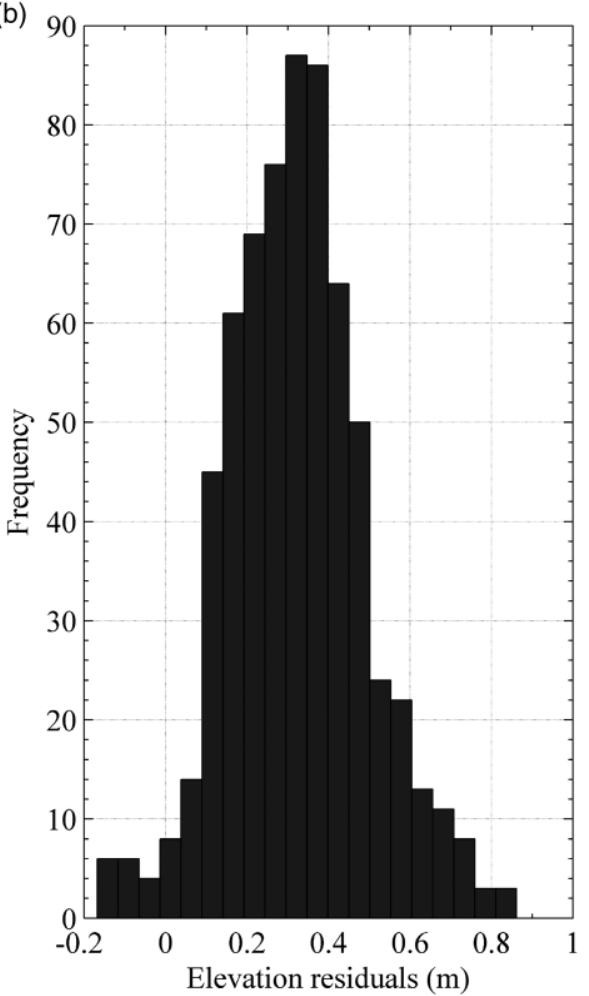

Figure 2 | (a) Normal probability plot with plus symbols representing the elevation residuals and the dotted line illustrates a linear fit of the probability-transformed data. (b) Histogram showing the distribution of the ALS elevation residuals for the study site.

be $-1.8 \mathrm{~m}$ for the maximum observed stage while the differences during the ALS survey and median stages were $-0.5 \mathrm{~m}$ and $-0.3 \mathrm{~m}$, respectively. For the UALS DTM, the differences in mean top width were found to be $-7.0 \mathrm{~m}$, $-6.1 \mathrm{~m}$, and $-4.1 \mathrm{~m}$ for the maximum observed stage, stage during the ALS survey, and median observed stage, respectively. Similar variability in differences was also seen with the wetted perimeter estimates. The largest difference in mean wetted perimeter of the ALS DTM was found to be $-1.6 \mathrm{~m}$ for the maximum observed stage while the differences during the ALS survey and median stage were $-0.3 \mathrm{~m}$ and $-0.1 \mathrm{~m}$, respectively. For the UALS DTM, the difference in mean wetted perimeter was found to be $-6.3 \mathrm{~m},-5.5 \mathrm{~m}$, and $-3.7 \mathrm{~m}$ for the maximum observed stage, stage during the ALS survey, and median observed stage, respectively. Looking at the mean cross-section area of flow for the ALS/ADCP DTM, the differences were fairly stable across all three stages with a range of values between $-0.4 \mathrm{~m}^{2}$ and $-0.6 \mathrm{~m}^{2}$. The differences in mean cross-section area of flow for the UALS/ADCP DTM, however, showed much more variability with values of $-3.2 \mathrm{~m}^{2},-1.3 \mathrm{~m}^{2}$, and $-0.6 \mathrm{~m}^{2}$ for the maximum observed stage, stage during the ALS survey, and median observed stage, respectively. Finally, the differences in mean hydraulic radii of the ALS/ADCP DTM were almost identical across all three stages while the UALS/ADCP DTM values ranged between $0.2 \mathrm{~m}$ and $0.4 \mathrm{~m}$.

\section{Rating curve comparison}

The empirical rating curve for the study site was derived from a gauging record provided by SMHI. A least squares polynomial was fit to the measurements following the form:

$Q=b_{0} h^{2}+b_{1} h+b_{2}$

where $Q$ is discharge, $h$ is stage, and $b_{0}, b_{1}$, and $b_{2}$ are constants with values $7.2 \mathrm{~s}^{-1},-91.8 \mathrm{~m} \mathrm{~s}^{-1}$, and $290.4 \mathrm{~m}^{3} \mathrm{~s}^{-1}$, respectively $\left(r^{2}=0.97\right)$. While Equation (9) is not a power law form typically implemented by monitoring agencies, 
Table 1 Stream properties calculated from DTMs based upon TS survey, corrected ALS and uncorrected ALS and ADCP data at three water depths representing the stage during the ALS survey, median observed stage, and maximum observed stage

\begin{tabular}{|c|c|c|c|c|c|}
\hline Stream channel property & $\begin{array}{l}\text { TS/ } \\
\text { ADCP }\end{array}$ & $\begin{array}{l}\text { ALS/ } \\
\text { ADCP }\end{array}$ & $\begin{array}{l}\text { UALS/ } \\
\text { ADCP }\end{array}$ & $\begin{array}{l}\text { Difference } \\
\text { (TS vs. ALS) }\end{array}$ & $\begin{array}{l}\text { Difference } \\
\text { (TS vs. } \\
\text { UALS) }\end{array}$ \\
\hline $\begin{array}{l}\text { Stage during ALS } \\
\text { survey }(\mathrm{m})\end{array}$ & 7.5 & 7.5 & 7.5 & 0.0 & 0.0 \\
\hline Mean top width (m) & 15.1 & 14.6 & 11.0 & -0.5 & -4.1 \\
\hline $\begin{array}{l}\text { Mean wetted perimeter } \\
(\mathrm{m})\end{array}$ & 17.3 & 17.0 & 13.6 & -0.3 & -3.7 \\
\hline $\begin{array}{l}\text { Mean cross-section } \\
\text { area }\left(\mathrm{m}^{2}\right)\end{array}$ & 22.7 & 22.3 & 22.1 & -0.4 & -0.6 \\
\hline $\begin{array}{l}\text { Mean hydraulic radius } \\
\text { (m) }\end{array}$ & 1.3 & 1.3 & 1.6 & 0.0 & 0.3 \\
\hline Median stage (m) & 7.8 & 7.8 & 7.8 & 0.0 & 0.0 \\
\hline Mean top width (m) & 17.2 & 16.9 & 11.1 & -0.3 & -6.1 \\
\hline $\begin{array}{l}\text { Mean wetted perimeter } \\
(\mathrm{m})\end{array}$ & 19.5 & 19.4 & 14.0 & -0.1 & -5.5 \\
\hline $\begin{array}{l}\text { Mean cross-section } \\
\text { area }\left(\mathrm{m}^{2}\right)\end{array}$ & 25.1 & 24.7 & 23.8 & -0.4 & -1.3 \\
\hline $\begin{array}{l}\text { Mean hydraulic radius } \\
\quad(\mathrm{m})\end{array}$ & 1.3 & 1.3 & 1.7 & 0.0 & 0.4 \\
\hline Maximum stage (m) & 8.1 & 8.1 & 8.1 & 0.0 & 0.0 \\
\hline Mean top width (m) & 23.4 & 21.6 & 16.4 & -1.8 & -7.0 \\
\hline $\begin{array}{l}\text { Mean wetted perimeter } \\
\quad(\mathrm{m})\end{array}$ & 25.8 & 24.3 & 19.5 & -1.6 & -6.3 \\
\hline $\begin{array}{l}\text { Mean cross-section } \\
\text { area }\left(\mathrm{m}^{2}\right)\end{array}$ & 31.2 & 30.7 & 28.0 & -0.6 & -3.2 \\
\hline $\begin{array}{l}\text { Mean hydraulic radius } \\
\text { (m) }\end{array}$ & 1.2 & 1.3 & 1.4 & 0.1 & 0.2 \\
\hline
\end{tabular}

Negative differences indicate an underestimation of the stream channel property while positive differences indicate an overestimation.

this polynomial form was selected as it had the best statistical fit and thereby gives the lowest possible error allowing for a robust comparison with our modeling effort. The empirical curve was determined without weighting any of the gauging measurements because additional metadata describing the quality of the gauging were not available. The gauging observations and empirical rating curve were used to evaluate the modeled rating curves (Figure 3). Note, we opted to include all gaugings, rather than filter out old or potentially poor quality gaugings as is often recommended (Sauer 2002), to avoid over-processing data and unintentionally biasing the curve fitting. For completeness, we tested the impact (analysis not shown) of filtering all but the gaugings taken after the last high-flow observation (reducing the number of gaugings to 28); however, while this of course reduced the absolute error of the empirical fitting, it did not change the main findings of our study since it also reduced the absolute error of the modeled rating curves.

In general, the modeled rating curves were in good agreement with the observations and empirical rating curve (Figure 3). The ALS/ADCP and TS/ADCP modeled rating curves were nearly identical except for a slight deviation at the highest gauged discharges where the ALS/ADCP model shows slightly lower values for the same stages. The uncorrected ALS/ADCP curve was similar to the ALS/ADCP and TS/ADCP curves but predicted lower discharges for stages higher than about $7.9 \mathrm{~m}$. A divergence between the empirical rating and the three modeled curves can be seen starting approximately from the manually surveyed water surface (i.e., $9.3 \mathrm{~m}^{3} / \mathrm{s}$ ) and continuing through to the highest modeled discharge (i.e., $25 \mathrm{~m}^{3} / \mathrm{s}$ ). For this ALS-dominated portion of the rating curve, all three models underestimated the discharge when compared to the empirically fitted curve. Looking at the ADCP-dominated portion of the rating curves, the three models appear to slightly overestimate the discharge when compared to the empirical rating. At low flows (i.e., below about $2 \mathrm{~m}^{3} / \mathrm{s}$ ), the three models shift away from the empirical rating and this portion of the modeled ratings predict about $0.5 \mathrm{~m}^{3} / \mathrm{s}$ less than the observations.

Performance of the ALS/ADCP, UALS/ADCP, and TS/ADCP models was determined with the RMSE and sum of squared errors (SSE) statistics (Table 2). The statistics were calculated from the observed discharges and the lower, upper, and entire portions of the rating curves. The lower and upper rating curve sections were defined about the discharge during the ADCP survey (i.e., $9.23 \mathrm{~m}^{3} / \mathrm{s}$ ) which divides the ratings into ADCP-dominated and ALS-dominated spatial domains. It is clear that all three modeled rating curves have significantly lower errors than the empirical rating for all portions of the ratings. When comparing between the ALS/ADCP and TS/ADCP models, the ALS/ADCP shows slightly higher errors for all portions of the rating curve. Looking at the UALS/ADCP, the errors of the lower rating curve section are similar to those of the ALS/ADCP; however, the upper section and entire portion 


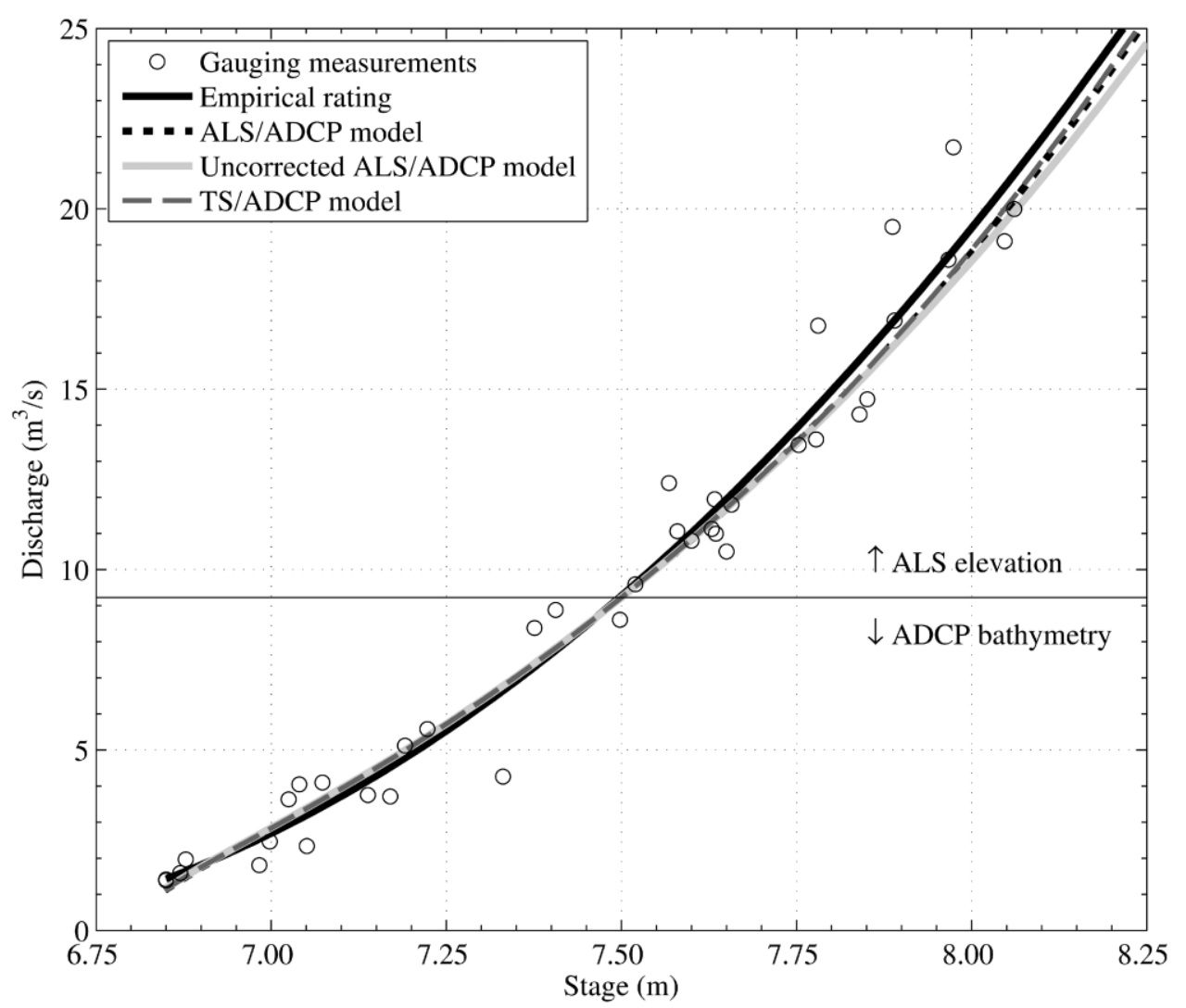

Figure 3 | Results of the modeled rating curves derived from ALS/ADCP (black dotted line), uncorrected ALS/ADCP (solid grey line), TS/ADCP (dashed line), and the empirical rating curve (solid black line) derived from the gauging measurements (circles). The horizontal black line illustrates the water surface during the ADCP survey and divide between the ALS- and ADCP-dominated portions of the rating curves.

of the ratings show much higher errors than the TS/ADCP and ALS/ADCP models.

\section{DISCUSSION}

\section{Coupling ALS and ADCP data}

Our results highlight the ability to generate rating curves from ALS data in combination with ADCP data. Although we find our results to be encouraging, some caveats should be considered when interpreting these results. For example, our analysis of the ALS data showed an intrinsic overestimation of the streambank elevation when compared to the reference TS survey. To overcome this and allow for improved rating curve modeling, elevation residuals were derived from a high-accuracy TS survey of the stream reach and an RMSE statistic was used as a block correction to correct the vertical error. Although this correction method proved to be effective for this study, it of course may not be practical where reference data are not available. One potential solution for collecting the required elevation data could be the use of unmanned aerial vehicles to acquire high-resolution aerial photos during leaf off conditions. From these images, high-resolution DTMs of the streambanks could be generated with photogrammetric methods such as structure from motion which has been shown to be cost-effective for mapping complex terrain (Westoby et al. 20I2; Javernick et al. 20I4). Although such DTMs would not be able to record the elevations below dense vegetation, open areas with good ground visibility could be used to correct portions of the ALS data.

In addition, when considering the $\mathrm{ADCP}$ bathymetry, we were not able to verify the accuracy of the depth measurements with another data source, such as a manual survey because the water was too deep to wade (i.e., mean 


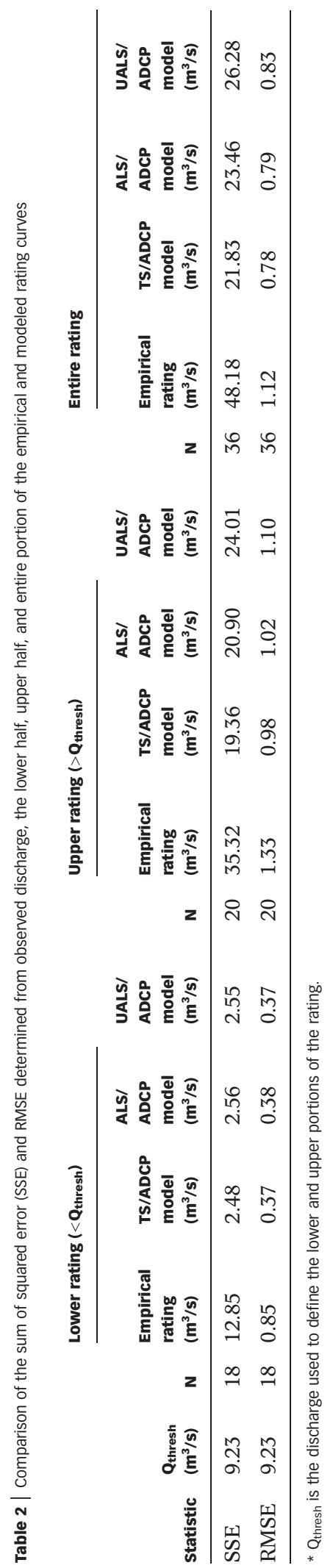

depth $=2.4 \mathrm{~m}$ ). This is a common challenge when collecting bathymetry; however, laboratory tests have shown that bathymetric errors for acoustic Doppler depths sounders are generally within a 5\% margin (González-Castro \& Muste 2007). From the perspective of hydrometric agencies, collecting the ADCP bathymetry would not require large amounts of additional effort in the field. In our case, the ADCP survey took approximately 3 hours to complete, including instrument setup time. For our site, gauging measurements have been collected approximately two to three times per year to capture the annual low and high flows. Adding bathymetric sampling via ADCP and RTK-GPS to the annual gauging surveys could be a useful tool for understanding and identifying morphological changes (and subsequent rating curve shifts) for sites similar to the Röån River.

An evaluation of stream channel geometry based upon DTMs derived from the ALS and ADCP was conducted at three representative stages (Table 1). The results showed that variations in the top width property could indicate a bias in the corrected ALS water boundary identification. At first glance, the top width property would appear to provide some indication for how well the location of the water boundary is represented by the ALS. However, the difference in surveying methods (i.e., TS transect vs. ALS areal) could result in an under-representation of the streambank topography during the TS survey thereby biasing the top width results. It is also likely that the ALS captured topographic features that were otherwise missed by the TS transect survey and is therefore an advantage of the ALS. Classification of the water boundary from pre-existing property and road maps, as was done with the Swedish national scan, would certainly have some varying effect on the top width due to the temporal and spatial differences between the data. Furthermore, it is probable that laser echoes from the partially submerged vegetation (i.e., sedges), found approximately $0.5 \mathrm{~m}$ from the water's edge, further biased the ALS-derived top width. It is clear that the current method for identification and delineation of Swedish water boundaries within the national ALS scan could be improved. Although the ALS showed variability for representing the top width, the range of the mean cross-section areas was found to be relatively small (i.e., between $-0.6 \mathrm{~m}^{2}$ and $-0.4 \mathrm{~m}^{2}$ which is less than a $2 \%$ difference) and indicates that the corrected ALS is appropriate for 
capturing stream channel topography. This is encouraging as accurate discharge estimations are dependent on accurate representation of the cross-section area. Therefore, we believe that both the RMSE elevation correction and national-scale ALS were appropriate for acquiring stream channel geometry for the Röån River.

\section{On the potentials for modeling rating curves}

The rating curve derived from the ALS/ADCP information proved to have a much lower SSE and RMSE than the empirical rating (Table 2). The empirical curve was determined from a standard least squares method without weighting any of the gauging measurements. Therefore, the upper portion of the rating potentially biases the entire rating curve due to the higher spread of the gauging measurements. Since additional metadata describing the quality of the gaugings were not available, weighting the observations was not considered in this study. Furthermore, these results are based upon the assumption that the polynomial fitted rating curve represents the 'true' rating. As such, other fitting methods (e.g., power law) as well as uncertainties in stage and discharge measurements (e.g., McMillan \& Westerberg 2015) could lead to different results. This might be particularly true when extrapolating beyond the observed gaugings where the physical basis of the modeling can be leveraged.

The accuracy of the modeled rating curve is also directly tied to the accuracy of the roughness parameters used in the model. Although there are different methods for determining the total flow resistance within a stream channel (Powell 20I4), the model used in this study (Kean \& Smith 2005) separates flow contributions from the stream channel bed and vegetation. The streambed roughness height was determined from two water surface slope surveys and reference discharge measurements for two flow conditions. Ideally, additional discharge and water-surface slope measurements should be collected for both very low and very high flow events to verify $z_{o}$ and to quantify any changes in the water surface slope. However, such events rarely occur and discharge measurements at high and low extremes are generally prone to higher levels of uncertainty.

With regards to flow resistance due to vegetation, the hydraulic model only considers form drag on woody vegetation determined from stem density measurements. While we believe that resistance due to vegetation was well represented, effects due to seasonal variations in vegetation state were not considered in this study. However, to evaluate the potential effects of seasonal changes in vegetation on the rating curve, we calculated a rating curve based on a vegetation stem density that was twice as dense as observed. At bankfull stage (i.e., $8.25 \mathrm{~m}$ ), the calculated discharge with denser vegetation resulted in a discharge that was only $0.4 \%$ lower than was modeled using the observed stem density. This result suggests that, at this site, seasonal changes in vegetation density are unlikely to have a substantial effect on the stage-discharge relation.

\section{On applicability for other sites}

The method presented should be applicable for sites with similar stream characteristics as the Röån River (i.e., uniform bed material, no large obstructions to flow, small diameter riparian vegetation). With regards to the application of the ADCP for collecting bathymetry, these instruments require a minimum operational water depth (e.g., M9 $=0.5 \mathrm{~m}$ ). For streams shallower than the minimum operational water depth, manual surveys of bathymetry would be more appropriate, which has been demonstrated in previous applications of the model (Kean \& Smith 2005, 20I0; Nathanson et al. 2012). Limitations could also exist for very large and deep rivers where complex hydraulic interactions such as backwater effects due to dams (Pajic et al. 20I4) could also pose challenges for our method. However, such complex flow conditions would be challenging for any 1-D model. For sites prone to looped ratings or hysteresis effects, these conditions can be simulated with the model, given measurements of the water surface slope for the rising and falling limb of the flood wave. Although this scenario was not investigated in this study, it is theoretically possible to accomplish given the current model structure.

\section{$\overline{\text { CONCLUSION }}$}

In this pilot study, we generated rating curves from coupled national-scale ALS data with ADCP bathymetry. The mean vertical error of the ALS was corrected through a block adjustment with an RMSE computed from a TS survey. The vertical correction was appropriate for our study but lack of reference elevation data could pose challenges at some 
other sites. DTMs derived from the coupling of ALS and ADCP bathymetry were evaluated for capturing stream channel properties as well as their suitability for use within a 1-D hydraulic model. The results indicated that although some variability was present for the estimated channel top width and area, the error incurred by the modeled rating curve was less than that of the empirical rating used for validation. Nonetheless, the ability of capturing detailed stream channel geometry with national-scale ALS data and ADCP bathymetry is encouraging because these data are required for parameterizing various hydraulic models (e.g., HEC-RAS, MIKE 11). As such, we consider our findings promising as national-scale ALS and ADCP instrumentation can be leveraged to reduce the cost and effort required for generating rating curves at gauging stations similar to the study site. Although the Röån River can be considered a typical inland stream in Sweden, the methods presented in this study should be further applied to different datasets and test sites to ensure their wider applicability.

\section{ACKNOWLEDGEMENTS}

This work was financially supported in part by the Swedish Research Council (VR Grant No. 2011-4390), the Swedish Research Council Formas (Project Number 942-2015-321), Carl Mannerfelts Fund, and Ahlmanns Fund. We thank Josefin Klein for helping with the fieldwork, Niklas Strömbeck and Mattias Ryman for collecting the acoustic Doppler current profiler surveys and the Swedish Metrological and Hydrological Institute for providing the stage-discharge measurements. We also thank J. Toby Minear at the U.S. Geological Survey and the two anonymous journal reviewers for their thorough and constructive comments that greatly improved this study. Any use of trade, product, or firm names is for descriptive purposes only and does not imply endorsement by the U.S. Government.

\section{REFERENCES}

Abdullah, Q., Maune, D., Smith, D. \& Heidemann, H. K. 2015 ASPRS positional accuracy standards for digital geospatial data. Am. Soc. Photogramm. Remote Sens. 81, A1-A26.
Barber, D., Mills, J. \& Smith-Voysey, S. 2008 Geometric validation of a ground-based mobile laser scanning system. ISPRS J. Photogramm. Remote Sens. 63, 128-141. doi: 10.1016/j. isprsjprs.2007.07.005.

Brasington, J., Vericat, D. \& Rychkov, I. 2012 Modeling river bed morphology, roughness, and surface sedimentology using high resolution terrestrial laser scanning. Water Resour. Res. 48, doi: 10.1029/2012WR012223.

Bullard, J. E., Mctainsh, G. H. \& Martin, P. 2007 Establishing stage-discharge relationships in multiple-channelled, ephemeral rivers: a case study of the Diamantina River, Australia. Geog. Res. 45, 233-245. doi: 10.1111/j.1745-5871. 2007.00457.x.

Casas, A., Benito, G., Thorndycraft, V. R. \& Rico, M. 2006 The topographic data source of digital terrain models as a key element in the accuracy of hydraulic flood modelling. Earth Surf. Process. Landforms 31, 444-456. doi: 10.1002/esp.1278.

Choo, T. H., Yoon, H. C. \& Lee, S. J. 2012 An estimation of discharge using mean velocity derived through Chiu's velocity equation. Environ. Earth Sci. 69, 247-256. doi: 10. 1007/s12665-012-1952-0.

Clayton, J. A. \& Kean, J. W. 2oro Establishing a multi-scale stream gaging network in the Whitewater River Basin, Kansas, USA. Water Resour. Manage. 24, 3641-3664. doi: 10.1007/s11269010-9624-x.

Ekström, S. 2013 Brownification of freshwaters - The role of dissolved organic matter and iron. PhD thesis, Lund University, Sweden.

Glennie, C. L., Carter, W. E., Shrestha, R. L. \& Dietrich, W. E. 2013 Geodetic imaging with airborne LiDAR: the Earth's surface revealed. Reports Prog. Phys. 76, 086801. doi: 10.1088/00344885/76/8/086801.

González-Castro, J. \& Muste, M. 2007 Framework for estimating uncertainty of ADCP measurements from a moving boat by standardized uncertainty analysis. J. Hydraul. Eng. 133, 1390-1410.

Gordon, R. L. 1996 Acoustic Doppler current profiler principles of operation - A practical primer. RD Instruments, San Diego, CA, USA.

Guenther, G. C., LaRocque, P. E. \& Lillycrop, W. J. 1994 Multiple surface channels in SHOALS airborne lidar. In SPIE: Ocean Optics XII, Bergen, Norway, pp. 422-430.

Guenther, G. C., Cunningham, A. G., Larocque, P. E., Reid, D. J., Service, N. O., Highway, E. \& Spring, S. 2000 Meeting the accuracy challenge in airborne lidar bathymetry. EARSeL eProceedings 1, 1-27.

Guerrero, J. L., Westerberg, I. K., Halldin, S., Xu, C.-Y. \& Lundin, L.-C. 2012 Temporal variability in stage-discharge relationships. J. Hydrol. 446-447, 90-102. doi: 10.1016/j. jhydrol.2012.04.031.

Harpold, A. A., Marshall, J. A., Lyon, S. W., Barnhart, T. B., Fisher, B. A., Donovan, M., Brubaker, K. M., Crosby, C. J., Glenn, N. F., Glennie, C. L., Kirchner, P. B., Lam, N., Mankoff, K. D., McCreight, J. L., Molotch, N. P., Musselman, K. N., Pelletier, J., Russo, T., Sangireddy, H., Sjöberg, Y., Swetnam, T. \& 
West, N. 2015 Laser vision: lidar as a transformative tool to advance critical zone science. Hydrol. Earth Syst. Sci. 19, 2881-2897. doi: 10.5194/hess-19-2881-2015.

Hartzell, P. J., Glennie, C. L. \& Finnegan, D. C. 2013 Calibration of a terrestrial full waveform lasers Scanner. In: ASPRS 2013 Annual Conference Proceedings, Baltimore, MD, USA. p. 7.

Höfle, B., Vetter, M., Pfeifer, N., Mandlburger, G. \& Stötter, J. 2009 Water surface mapping from airborne laser scanning using signal intensity and elevation data. Earth Surf. Process Landforms 34, 1635-1649. doi: 10.1002/esp.1853.

Hohenthal, J., Alho, P., Hyyppä, J. \& Hyyppä, H. 20I Laser scanning applications in fluvial studies. Prog. Phys. Geogr. 35, 782-809. doi: 10.1177/0309133311414605.

Isenburg, M. 2015 LASTools - efficient tools for LiDAR research. Available at: http://rapidlasso.com/ (accessed 27 May 2015).

Javernick, L., Brasington, J. \& Caruso, B. 2014 Modeling the topography of shallow braided rivers using Structure-fromMotion photogrammetry. Geomorphology 213, 166-182. doi: 10.1016/j.geomorph.2014.01.006.

Kean, J. W. \& Smith, J. D. 2005 Generation and verification of theoretical rating curves in the Whitewater River basin, Kansas. J. Geophys. Res. 110, 1-17. doi: 10.1029/ 2004JF000250.

Kean, J. W. \& Smith, J. D. 20Io Calculation of stage-discharge relations for gravel bedded channels. J. Geophys. Res. 115, 115. doi: 10.1029/2009JF001398.

Kinzel, P. J., Legleiter, C. J. \& Nelson, J. M. 2013 Mapping river bathymetry with a small footprint green LiDAR: applications and challenges. J. Am. Water Resour. Assoc. 49, 183-204. doi: 10.1111/jawr.12008.

Krishnan, S., Viswanath Nandigam, C., Crosby, M. P., Cowart, C., Baru, C. \& Arrowsmith, R. 20II OpenTopography: a services oriented architecture for community access to LIDAR topography. In: COM.Geo '11 Proceedings of the 2nd International Conference on Computing for Geospatial Research \& Applications, New York, USA.

Lam, N., Nathanson, M., Lundgren, N., Rehnström, R. \& Lyon, S. W. 2015 A cost-effective laser scanning method for mapping stream channel geometry and roughness. JAWRA J. Am. Water Resour. Assoc. 51, 1211-1220. doi: 10.1111/17521688.12299.

Lantmäteriet 2012 Produktbeskrivning: Laserdata (Dokumentversion 1.4) (Product description). Available at: https://www.lantmateriet.se/globalassets/kartor-ochgeografisk-information/hojddata/produktbeskrivningar/ laserdat.pdf 1-16.

Legleiter, C. J. 2012 Remote measurement of river morphology via fusion of LiDAR topography and spectrally based bathymetry. Earth Surf. Process. Landforms 37, 499-518. doi: 10.1002/esp.2262.

Legleiter, C. J. 20I5 Calibrating remotely sensed river bathymetry in the absence of field measurements: Flow REsistance Equation-Based Imaging of River Depths (FREEBIRD). Water Resour. Res. 51, 2865-2884. doi: 10.1002/ 2014WR016624.
Legleiter, C. J. \& Roberts, D. A. 2009 A forward image model for passive optical remote sensing of river bathymetry. Remote Sens. Environ. 113, 1025-1045. doi: 10.1016/j.rse.2009.01. 018.

Legleiter, C. J., Kyriakidis, P. C., Mcdonald, R. R. \& Nelson, J. M. 20II Effects of uncertain topographic input data on twodimensional flow modeling in a gravel-bed river. Water Resour. Res. 47, 1-24. doi: 10.1029/2010WR009618.

Leonard, J., Mietton, M., Najib, H. \& Gourbesville, P. 2000 Rating curve modelling with Manning's equation to manage instability and improve extrapolation. Hydrol. Sci. J. 45, 739750. doi: 10.1080/02626660009492374.

Long, C. E., Wiberg, P. L. \& Nowell, A. R. M. 1993 Evaluation of von Karman's constant from integral flow parameters. J. Hydraul. Eng. 119, 1182-1190.

Lyon, S., Nathanson, M., Lam, N., Dahlke, H., Rutzinger, M., Kean, J. \& Laudon, H. 2015 Can low-resolution airborne laser scanning data be used to model stream rating curves?. Water 7, 1324-1339. doi: 10.3390/w7041324.

Mandlburger, G., Hauer, C., Höfle, B., Habersack, H. \& Pfeifer, N. 2009 Optimisation of LiDAR derived terrain models for river flow modelling. Hydrol. Earth Syst. Sci. 13, 1453-1466. doi: 10.5194/hess-13-1453-2009.

Mandlburger, G., Hauer, C., Wieser, M. \& Pfeifer, N. 20I5 Topobathymetric LiDAR for monitoring river morphodynamics and instream habitats - a case study at the Pielach River. Remote Sens. 7, 6160-6195. doi: 10.3390/rs70506160.

Marcus, W. A., Legleiter, C. J., Aspinall, R. J., Boardman, J. W. \& Crabtree, R. L. 2003 High spatial resolution hyperspectral mapping of in-stream habitats, depths, and woody debris in mountain streams. Geomorphology 55, 363-380. doi: 10. 1016/S0169-555X(03)00150-8.

McDonald, R. R., Nelson, J. M. \& Bennett, J. P. 2005 Multidimensional surface-water modeling system user's guide: U.S. Geological Survey Techniques and Methods. 6-B2, p. 136.

McKean, J., Tonina, D., Bohn, C. \& Wright, C. 2014 Effects of bathymetric lidar errors on flow properties predicted with a multi-dimensional hydraulic model. J. Geophys. Res. Earth Surf. 119, 644-664. doi: 10.1002/2013JF002897.

McMillan, H. K. \& Westerberg, I. K. 20I5 Rating curve estimation under epistemic uncertainty. Hydrol. Process. 29, 1873-1882. doi: 10.1002/hyp.10419.

McMillan, H., Krueger, T. \& Freer, J. 2012 Benchmarking observational uncertainties for hydrology: rainfall, river discharge and water quality. Hydrol. Process. 26, 4078-4111. doi: 10.1002/hyp.9384.

Mueller, D. S. \& Wagner, C. R. 2009 Measuring discharge with acoustic Doppler current profilers from a moving boat. US Geol. Surv. Tech. Methods 72, doi: 10.3133/tm3A22.

Nathanson, M., Kean, J. W., Grabs, T. J., Seibert, J., Laudon, H. \& Lyon, S. W. 2012 Modelling rating curves using remotely sensed LiDAR data. Hydrol. Process. 26, 1427-1434. doi: 10. 1002/hyp.9225.

Pajic, P., Andjelic, L., Urosevic, U. \& Polomcic, D. 20I4 Evaluation of melioration area damage on the river Danube caused by 
the hydroelectric power plant 'Djerdap 1' backwater. Water Sci. Technol. 70 (2), 376-385. doi: 10.2166/wst.2014.230.

Pelletier, P. 1988 Uncertainties in the single determination of river discharge: a literature review. Can. J. Civ. Eng. 15, 834-850.

Powell, D. M. 20I4 Flow resistance in gravel-bed rivers: progress in research. Earth Sci. Rev. 136, 301-338. doi: 10.1016/j. earscirev.2014.06.001.

Reistad, S. K., Petersen-Øverleir, A. \& Bogetveit, L. J. 2007 Setting up rating curves using HEC-RAS. J. Nor. Water Assoc. 3, 20-30.

Rennie, C. D. \& Church, M. 20Io Mapping spatial distributions and uncertainty of water and sediment flux in a large gravel bed river reach using an acoustic Doppler current profiler. J. Geophys. Res. 115, F03035. doi: 10.1029/2009JF001556.

Sauer, V. B. 2002 Standards for the analysis and processing of surface-water data and information using electronic methods. US Geological Survey Water-Resources Investigation Report 01-4044, 91.

Shan, J. \& Toth, K. 2009 Topographic Laser Ranging and Scanning: Principles and Processing. CRC Press, Boca Raton, FL, USA.

SMHI 2014 Hydrologiska grundnätet. Available at: http://www. smhi.se/professionella-tjanster/professionella-tjanster/miljooch-klimat/vattenmiljo/hydrologiska-grundnatet-1.27699 (accessed 20 October 2014).

SonTek 20II RiverSurveyor S5/M9 system manual. SonTek, San Diego, CA, USA.

Trimble 20I3 Trimble S6 DR plus datasheet. Trimble, Sunnyvale, CA, USA.

Vaaja, M., Kukko, A., Kaartinen, H., Kurkela, M., Kasvi, E., Flener, C., Hyyppä, H., Hyyppä, J., Järvelä, J. \& Alho, P. 2013
Data processing and quality evaluation of a boat-based mobile laser scanning system. Sensors (Basel) 13, 1249712515. doi: 10.3390/s130912497.

Wang, C. K. \& Philpot, W. D. 2007 Using airborne bathymetric lidar to detect bottom type variation in shallow waters. Remote Sens. Environ. 106, 123-135. doi: 10.1016/j.rse.2006. 08.003.

Wehr, A. \& Lohr, U. 1999 Airborne laser scanning - an introduction and overview. ISPRS J. Photogramm. Remote Sens. 54, 68-82. doi: 10.1016/S0924-2716(99)00011-8.

Westerberg, I., Guerrero, J.-L., Seibert, J., Beven, K. J. \& Halldin, S. 20II Stage-discharge uncertainty derived with a nonstationary rating curve in the Choluteca River, Honduras. Hydrol. Process. 25, 603-613. doi: 10.1002/hyp.7848.

Westoby, M. J., Brasington, J., Glasser, N. F., Hambrey, M. J. \& Reynolds, J. M. 2012 'Structure-from-Motion' photogrammetry: a low-cost, effective tool for geoscience applications. Geomorphology 179, 300-314. doi: 10.1016/j. geomorph.2012.08.021.

Williams, R. D., Rennie, C. D., Brasington, J., Hicks, D. M. \& Vericat, D. 2015 Linking the spatial distribution of bed load transport to morphological change during high-flow events in a shallow braided river. J. Geophys. Res. Earth Surf. 120, 604622. doi: 10.1002/2014JF003346.

Woodget, A. S., Carbonneau, P. E., Visser, F. \& Maddock, I. P. 20I5 Quantifying submerged fluvial topography using hyperspatial resolution UAS imagery and structure from motion photogrammetry. Earth Surf. Process. Landforms 40, 47-64. doi: 10.1002/esp.3613. 


\section{Author Queries}

Journal: Hydrology Research

Manuscript: HYDROLOGY-D-15-00257

No Queries 